\title{
Empoderamento e relações de poder: a cobertura feminista da Copa do Mundo da Rússia pelo projeto dibradoras
}

\author{
Empowerment and power relations: the feminist coverage of the \\ Russian World Cup by the dibradoras project
}

\author{
Carolina Bortoleto Firmino \\ Universidade Estadual Paulista Júlio de Mesquita Filho (UNESP), Bauru/Brasil \\ Doutoranda em Comunicação, Universidade Estadual Paulista \\ carolina.bfirmino@gmail.com
}

\begin{abstract}
RESUMO: A representatividade feminina no esporte ganhou espaço com a oportunidade de debatê-la no ambiente plural da internet. Em sintonia com as demandas da sociedade, também surgiram conteúdos diferentes dos portais tradicionais de esporte, com o objetivo de promover a cobertura feminista no segmento. Neste contexto, o blog dibradoras acompanhou a Copa do Mundo de Futebol Masculino (Rússia, 14 de junho a 15 de julho de 2018), apoiado na compreensão do empoderamento como o processo de questionar ideologias e relações de poder. Para identificar a natureza dos questionamentos e medir a interação positiva ou negativa com a mensagem central da notícia, aplicamos a metodologia de análise de conteúdo em duas etapas. Definimos as categorias "posicionamento", "gênero em profundidade" e "empoderamento" para classificar os títulos dos 20 textos que formaram o corpus. Posteriormente, analisamos o total de 214 comentários, que foram em sua maioria negativos e emitidos por homens.
\end{abstract}

PalaVRaS-Chave: Gênero; Jornalismo esportivo; Empoderamento; Copa do Mundo.

ABSTRACT: The female representation in sport has gained space with the opportunity to debate it in the plural environment of the internet. In line with the demands of society, different contents of traditional sports portals have also appeared, with the objective of promoting feminist coverage in the segment. In this context, the dibradoras blog accompanied the Men's Soccer World Cup (Russia, June 14 to July 15, 2018), supported in the understanding of empowerment as the process of questioning ideologies and power relations. In order to identify the nature of the questions and to measure the positive or negative interaction with the central message of the news, we apply the methodology of content analysis in two stages. We defined the categories "positioning", "genre in depth" and "empowerment" to classify the titles of the 20 texts that formed the corpus. Subsequently, we analyzed the total of 214 comments, which were mostly negative and issued by men.

KEYwORDS: Gender; Sports Journalism; Empowerment; World Cup. 


\section{INTRODUÇÃ̃ ${ }^{1}$}

0 ano de 2015 foi cenário de mudanças significativas no que se refere ao protagonismo feminino no Brasil. Uma nova geração de mulheres ocupou as ruas e as redes sociais para reivindicar a igualdade de gênero e promover a luta contra o assédio sexual, a violência doméstica, o machismo, a criminalização do aborto e outras demandas. Neste movimento, que ficou conhecido como Primavera Feminista, as novas tecnologias de informação tiveram papel central na popularização de tais pautas.

Segundo dados da Agência Brasil,2 a busca pelo termo "feminismo" no Google aumentou 86,7\% entre janeiro de 2014 e outubro de 2015 - passando de 8.100 para 90.500 buscas; além disso, muitos blogs ganharam importância nacional com campanhas utilizando hashtags e compartilhando conteúdos alternativos aos dos grandes portais femininos de notícias. AzMina, Não Me Kahlo, Lado M, Empodere Duas Mulheres, Think Olga, Blogueiras Feministas, dibradoras, Frida Diria e Capitolina foram alguns dos canais de informação que se projetaram desta forma, todos conduzidos por mulheres.

No âmbito de discussões sobre a atuação de mulheres no cenário esportivo, o projeto dibradoras repercutiu com mais destaque, principalmente a partir de 2016. Isso porque, com a realização das Olimpíadas do Rio de Janeiro (que ocorreu no período entre 05 e 21 de agosto), o debate sobre a representatividade feminina no esporte se fez ainda mais presente no país. As idealizadoras propuseram "driblar preconceitos e mostrar que mulheres podem gostar, entender e praticar esporte" ${ }^{3}$

Hoje, o dibradoras está no Twitter, Instagram e Facebook, além de manter um podcast semanal na plataforma Central 3. No Facebook, a página conta com 31 mil curtidas ${ }^{4}$ - sendo que, na primeira semana do evento olímpico, houve um aumento de $24 \%$ nos acessos e $335 \%$ no número de curtidas. Durante as duas

\footnotetext{
${ }^{1}$ Trabalho apresentado no III Simpósio Internacional de Estudos sobre Futebol, em setembro de 2019, organizado pelo Museu do Futebol, LUDENS (FFLCH-USP), Ludopédio e pela PUC-SP.

${ }^{2}$ Disponível em: http://bit.ly/2Q4euhV.

${ }^{3}$ Descrição disponível em: https://dibradoras.blogosfera.uol.com.br.

${ }^{4}$ Consulta feita no dia 07 maio 2019; dados oficiais fornecidos pela página.
} 
semanas de Jogos Olímpicos, a hashtag \#MaisQueMusas tomou as redes sociais digitais impulsionada pela cobertura do dibradoras, que diariamente apresentava quem eram as atletas que estavam competindo no evento, com foco em sua trajetória profissional e qualidades técnicas.

Em 2018, passou a integrar o catálogo de blogs do UOL Esporte para levar discussões sobre gênero e esporte para um público que é majoritariamente formado por homens. Uma pesquisa realizada em 2016 pelo Instituto Ipsos em nove regiões metropolitanas do Brasil mostrou que a maioria dos fãs de esporte é formada por homens (61\%). Entre os entrevistados, $76 \%$ estão conectados à Internet; deles, 29\% consomem notícias esportivas online.

Com uma abordagem feminista, o blog dialoga sobre o ciclo de discursos normativos perpetuados ao longo da história e a necessidade de empoderar mulheres para questionar ideologias e relações de poder. Dessa forma, sua presença no ambiente esportivo remete à ideia de mudança e ressignificação de papéis sociais. Neste artigo, consideramos que o feminismo seja o movimento que impulsiona o cenário a mudar e permite à mulher exercer esses novos papéis, funcionando como ameaça e complementaridade: ${ }^{5}$

\begin{abstract}
a presença da mulher no mundo do esporte representa, ao mesmo tempo, ameaça e complementaridade: ameaça porque chama para si a atenção de homens e mulheres, dentro de um universo construído e dominado por valores masculinos e porque põe em perigo algumas características tidas como constitutivas da sua feminilidade. Complementaridade porque parceira do homem em atitudes e hábitos sociais, cujo exercício simboliza um modo moderno e civilizado de ser. 6
\end{abstract}

Nos tópicos a seguir, refletimos sobre os impactos dos movimentos sociais em rede na construção de novas narrativas para as mulheres no esporte e sobre a ação de atores sociais que compõem a nova cena em que se articula a subversão de padrões, ideias ou comportamentos preestabelecidos e propagados como verdades únicas.

\footnotetext{
${ }^{5}$ GOELLNER. Mulheres e esporte: sobre conquistas e desafios, p. 89.

${ }^{6}$ GOELLNER. Mulheres e esporte: sobre conquistas e desafios, p. 89.
} 
Os atores da mudança social são capazes de exercer influência decisiva utilizando mecanismos de construção do poder que correspondem às formas e aos processos do poder na sociedade em rede. Envolvendo-se na produção de mensagens nos meios de comunicação de massa e desenvolvendo redes autônomas de comunicação horizontal, os cidadãos da era da informação tornam-se capazes de inventar novos programas para as suas vidas com as matérias-primas de seu sofrimento, suas lágrimas, seus sonhos suas esperanças. Elaboram seus projetos compartilhando sua experiência. Subvertem a prática da comunicação tal como usualmente se dá, ocupando o veículo e criando a mensagem. Superam a impotência de seu desespero solitário colocando em redes seu desejo. Lutam contra poderes constituídos identificando as redes que os constituem. ${ }^{7}$

O empoderamento de mulheres neste contexto implica na conquista da autonomia e da autodeterminação, além de se tratar tanto de um instrumento um meio, um mecanismo - como de um fim em si próprio - o propósito, ainda que não seja absoluto. 8

E trata-se, para nós, ao mesmo tempo, de um instrumento/meio e um fim em si próprio. 0 empoderamento das mulheres implica, para nós, na libertação das mulheres das amarras da opressão de gênero, da opressão patriarcal. Para as feministas latino-americanas, em especial, o objetivo maior do empoderamento das mulheres é questionar, desestabilizar e, por fim, acabar com o a ordem patriarcal que sustenta a opressão de gênero. ${ }^{9}$

O caminho de conexões apresentado por Castells coloca pessoas dividindo redes de luta contra poderes constituídos e aponta para a compreensão feminista de que o empoderamento se trata de uma conquista coletiva. Ou seja, ainda que haja o empoderar-se como ação individual - da autoestima e da autoconfiança - reconhecê-lo coletivamente é conectar contextos políticos, históricos e sociais. 0 empoderamento indica para o feminismo uma alteração radical dos processos e das estruturas que reproduzem a posição subordinada das mulheres como gênero. ${ }^{10}$

Com o objetivo de romper com tais processos e estruturas, destacamos a cobertura da Copa do Mundo de Futebol Masculino (Rússia, 2018) realizada

\footnotetext{
${ }^{7}$ CASTELLS. Redes de indignação e esperança: movimentos sociais na era da internet, p. 18.

${ }^{8}$ SARDENBERG. Da crítica feminista à ciência a uma ciência feminista?, p. 2.

9 SARDENBERG. Da crítica feminista à ciência a uma ciência feminista?, p. 2.

${ }^{10}$ LÉON. Poder y empoderamiento de las mujeres, p. 25-45.
} 
pelo projeto dibradoras. Entendemos que há uma quebra de paradigma quando um grupo formado apenas por mulheres oferece uma interpretação feminista do maior e mais popular evento esportivo masculino. As partidas aconteceram entre os dias 14 de junho e 15 de julho, período no qual 22 textos foram publicados no endereço dibradoras.blogosfera.uol.com.br - desses, dois não eram referentes à Copa. Assim, definem-se os 20 textos que compõem nosso corpus de análise.

A metodologia de análise de conteúdo foi aplicada em duas etapas: primeiro, na classificação dos títulos de acordo com as categorias detalhadas a seguir. São elas: posicionamento, gênero em profundidade e empoderamento. $\mathrm{Na}$ primeira, consideramos os títulos que se posicionam contra ou a favor de algo, respaldados na crítica à neutralidade nos estudos feministas e novas práticas de pesquisa científica; na segunda, aqueles que incentivam a reflexão a partir de um problema de gênero no contexto esportivo; por fim, na terceira, os títulos que defendem o espaço e o lugar de fala de mulheres (atletas, jornalistas, torcedoras) e valorizam iniciativas no âmbito esportivo.

Depois de dividir os títulos por categoria, somamos todos os comentários presentes nos textos para medir a interação positiva, negativa ou neutra do internauta com o conteúdo (ou seja, que tipo de reação a pessoa que comentava tinha sobre o texto), e classificar esse internauta quanto ao gênero (feminino, masculino ou indefinido). Importante destacar que observamos o nome de usuário e a concordância de gênero para fazer essa classificação e que consideramos os comentários feitos até o dia 27 de setembro de 2018. Além disso, encontramos divergências entre a quantidade de comentários indicada no blog e os comentários que realmente estavam disponíveis - chegamos a 214, mas a soma dos números gerados automaticamente era de 332.

\section{NOVAS PERSPECTIVAS DE MOBILIZAÇÃO}

A preocupação em representar minorias acompanhou o crescimento do acesso às novas tecnologias e da propagação de ideias por meio das redes sociais 
digitais. ${ }^{11}$ Em 2012, o Facebook - rede criada por Mark Zuckerberg - atingiu a marca de um bilhão de usuários ativos no mundo, o que significou um bilhão de pessoas conectadas entre si. ${ }^{12}$ Naquele mesmo ano, para além do trabalho dos profissionais da comunicação, assistimos a pessoas comuns - ainda que com menor alcance - documentando informalmente o maior evento esportivo do mundo, cuja edição estava acontecendo em Londres. Elas utilizavam seus dispositivos móveis para fotografar, filmar e compartilhar detalhes da competição e da rotina dos atletas em seus próprios perfis online.

Essa foi uma significativa demonstração da mudança no acesso às novas tecnologias em relação ao ciclo olímpico de Pequim (2008), que modificaram não só os hábitos de consumo de conteúdo, mas também de produção. Na época, esse quadro resultou em dificuldades técnicas para o próprio Comitê Olímpico Internacional (COI) e para quem realizava a cobertura noticiosa dos Jogos. Alguns enfrentaram problemas de congestionamento das redes de conexão e tiveram suas transmissões prejudicadas, assim como o funcionamento de GPS, em função da quantidade elevada de envio e recebimento de dados.

No Brasil, aconteceu simultaneamente a consolidação do Facebook como a rede social digital mais popular no país - a exemplo futuro das mobilizações conhecidas como Jornadas de Junho de 2013, que começaram a se organizar nas redes sociais digitais e seguiram para as ruas. Grandes veículos de comunicação precisaram buscar alternativas para se reinventarem, enquanto outros menores e que já vinham atuando de forma independente, encontraram oportunidade para se fortalecerem midiaticamente e empoderarem diferentes grupos:

Nos últimos anos, a comunicação em ampla escala tem passado por profunda transformação tecnológica e organizacional, com a emergência do que denominei autocomunicação de massa, baseada em redes horizontais de comunicação multidirecional, interativa, na Internet; e, mais ainda, nas redes de comunicação sem fio, atualmente a principal plataforma de comunicação em toda parte. ${ }^{13}$

\footnotetext{
11 Optamos por utilizar o termo "redes sociais digitais", de Recuero (2009), para diferenciar redes sociais online e offline.

12 Disponível em: https://glo.bo/2VxsQ0h.

${ }^{13}$ CASTELLS. Redes de indignação e esperança, p. 128.
} 
Segundo pesquisa ${ }^{14}$ realizada pelo Instituto Reuters, vinculado à Universidade de Oxford, em 2016, o Brasil era o terceiro país que mais consumia notícias por meio do Facebook, e o primeiro no ranking de produção de conteúdo jornalístico online e interação dos usuários com o que é postado na rede. Diante desse cenário, para as Olimpíadas que aconteceriam no Rio de Janeiro, era preciso não só garantir uma infraestrutura que contemplasse as necessidades dos veículos de comunicação, mas promover modelos diferentes de cobertura que dessem conta da demanda tecnológica e social do momento. Surge, então, o que definimos aqui como "contracobertura ${ }^{15}$ esportiva", uma proposta de cobertura feminista ou de gênero no esporte. Nela, temos a apropriação de ferramentas de comunicação online e das redes sociais como recurso para contrapor a invisibilidade da mulher nas coberturas, combater o sexismo e apresentar perspectivas diferentes daquelas que naturalizam o esporte como campo masculino. A possibilidade de realizar essa contracobertura colocou em xeque o ciclo de abordagens normativas perpetuadas ao longo da história e trouxe desafios aos comunicadores:

A horizontalidade das redes favorece a cooperação e a solidariedade, ao mesmo tempo que reduz a necessidade de liderança formal. Assim, o que parece ser ineficaz como forma de deliberação e tomada de decisão é de fato o alicerce necessário para gerar confiança, sem a qual nenhuma ação comum poderia ser empreendida contra o cenário de uma cultura político caracterizada pela competição e pelo cinismo. 0 movimento produz seus próprios antídotos contra a disseminação dos valores sociais que deseja combater. Esse é o princípio constante que surge dos debates de todos os movimentos: não apenas os fins não justificam os meios, mas os meios, de fato, encarnam os objetivos da transformação. ${ }^{16}$

Passou-se a contemplar as vivências da mulher-atleta, do público feminino consumidor de esporte que se reconheceu nesse conteúdo e das jornalistas inseridas em um contexto de ressignificação da prática esportiva para mulheres. Os temas publicados tinham a preocupação de levantar algumas

\footnotetext{
${ }^{14}$ Disponível em: http://bit.ly/2w4ALmR.

15 O termo foi utilizado pela primeira vez para abordar a cobertura ativista dos protestos de Seattle em 1999, nos Estados Unidos.

${ }^{16}$ CASTELLS. Redes de indignação e esperança, p. 132.
} 
questões presentes nessa relação repleta de estereótipos: por que elas ainda gostam e praticam menos que os homens? Podemos dar outro sentido para a expressão lute como uma menina? Como a menstruação e a gravidez podem ser transformadas em vantagem para as atletas? Por que a ginástica artística é só para mulheres? A essa contracobertura também atribuímos a característica de ser uma leitura feminista, que se manifesta na defesa de pautas congruentes com o movimento - como direitos iguais, valorização da mulher no mercado de trabalho, maior representação feminina, entre outras - e ao assumir um posicionamento, fazendo com que o esporte também esteja incluído entre essas pautas.

\section{CONSTRUÇÃo DA METODOLOGIA E DAS CATEGORIAS DE ANÁLISE}

As discussões apresentadas aqui são um pequeno recorte do aporte teóricometodológico que deve compor a tese final que estuda a cobertura esportiva feminista do projeto dibradoras. Nesta etapa do artigo, abordamos a descrição resumida das categorias de análise de conteúdo que utilizamos para classificar os títulos dos textos escolhidos como corpus. São elas: posicionamento, gênero em profundidade e empoderamento. 0 ponto de partida para defini-las foi questionar quais são as características-chave que garantem a natureza feminista de uma publicação.

\section{Posicionamento}

Assumir o pertencimento tem feito parte das novas correntes epistemológicas que contestam a existência de neutralidade e controle da objetividade. Nesse caso, o construcionismo social, o construtivismo radical, o pós-modernismo e o feminismo aprofundam-se como crítica às abordagens estruturalistas, em defesa de leituras inovadoras que não diminuem o rigor da pesquisa. ${ }^{17} \mathrm{~A}$ lógica dessas correntes, sustentam que 1) o conhecimento é válido se for uma

\footnotetext{
${ }^{17}$ NEVES; NOGUEIRA. A psicologia feminista e a violência contra as mulheres na intimidade, p. $43-64$.
} 
representação correta, 2) o objeto é um elemento constitutivo do mundo, 3) a realidade é independente de nós e 4) a verdade é um critério de decisão. ${ }^{18}$

Por outro lado, as possibilidades de se romper com tais impasses começaram a surgir, com avanços tecnológicos e metodológicos, no interior do pensamento feminista, que buscam teorizar as relações de gênero. Utilizar o gênero como objeto de investigações feministas, tem "permitido não apenas a abertura de novas fronteiras para reflexão e análise, como também a solidificação das bases para a construção de uma epistemologia feminista”. ${ }^{19}$ Entendemos que não só como objeto de estudo, mas empiricamente, o campo esportivo se manifesta como sistema a ser modificado: proibições e preconceitos combatidos ao longo de décadas e a constante necessidade de legitimação de mulheres atletas.

\section{GÊNERO EM PROFUNDIDADE}

A relação das mulheres com o esporte atravessa um momento de mudanças. Além do aumento na participação feminina em Olimpíadas nos últimos dez anos - hoje elas representam 47,4\% do total de atletas das delegações - existem iniciativas de inclusão tanto na gestão esportiva quanto em outras áreas que requerem representatividade, como no jornalismo esportivo e na formação de árbitras. No entanto, ainda que conquistas significativas estejam acontecendo, é preciso encarar esses espaços obtidos como exceções dentro de um contexto de preconceitos, proibições e invisibilidade históricos.

No início dos anos 2000 , pesquisadores ${ }^{20}$ buscaram identificar sob quais aspectos a mulher-atleta era representada e o resultado foi a utilização de cinco técnicas ou recortes a partir dos ideais de feminilidade: marcação de gênero, heterossexualidade compulsória, feminilidade apropriada, infantilização e minimização do esporte (tradução nossa). A marcação de gênero expõe a

\footnotetext{
${ }^{18}$ NEVES; NOGUEIRA. A psicologia feminista e a violência contra as mulheres na intimidade: a (re)construção dos espaços terapêuticos, p. 43-64.

${ }^{19}$ SARDENBERG. Da crítica feminista à ciência a uma ciência feminista?, p. 6.

${ }^{20}$ WENSING; BRUCE; POPE. Playing to win or trying your best, p. 203-219.
} 
diferença entre eventos ou esportes de homens e eventos ou esportes de mulher; a heterossexualidade compulsória considera mulheres como objetos sexuais ou nos papéis de esposas ou mães; a feminilidade apropriada enfatiza estereótipos a partir de aspectos considerados femininos, como fraqueza física ou emocional, lágrimas e preocupação com os outros; a infantilização representa os termos utilizados para se referir a mulheres atletas (meninas) e homens atletas (homens); por fim, a minimização do esporte se dá quando a abordagem é feita a partir de outras perspectivas, como a aparência, os relacionamentos amorosos ou a orientação sexual, que diminuem a identificação com o esporte. Por mais que a pesquisa tenha sido realizada há quase duas décadas, tais recortes ainda são recorrentes em coberturas atuais. No entanto, não temos a pretensão de eliminar todas as discussões sobre cada um deles, mas de usá-los para projetar elementos que contribuam para a construção de nossa metodologia.

\section{EMPODERAMENTO}

O termo empoderamento vem da palavra empowerment e, quando se conecta ao feminino, pode ser descrito como a capacidade das mulheres de ter controle sobre a própria vida, suas vontades e seus corpos. ${ }^{21}$ Ele também aparece como substituto para manifestações de integração, participação, autonomia, identidade, desenvolvimento e planejamento, não se limitando à sua origem emancipadora. No entanto, essa variedade de uso da palavra faz com que alguns significados se percam de seu real sentido, questão que motivou feministas da década de 1990 a preencherem esse vazio teórico. ${ }^{22}$

Neste contexto, surge a aplicação do empoderamento para transformação social a partir de uma concepção feminista de mundo; em que o empoderamento para o feminismo indica uma alteração radical dos processos e estruturas que reproduzem a posição subordinada das mulheres como gênero. ${ }^{23}$ Pensamos que

\footnotetext{
${ }^{21}$ LÉON. Poder y empoderamiento de las mujeres, p. 25-45.

22 LÉON. Poder y empoderamiento de las mujeres, p. 25-45.

${ }^{23}$ LÉON. Poder y empoderamiento de las mujeres, p. 25-45.
} 
estas definições são complementares e resultam uma da outra: não é possível que haja uma alteração radical na subordinação feminina se não houver uma quebra de paradigmas impulsionada por uma transformação social feminista.

0 momento é de rompimento com as estruturas habituais. As pautas que discutem a ocupação de espaços ou a criação de novos espaços para mulheres avançam, e caminham para o empoderamento inclusive no campo esportivo. A compreensão das mulheres sobre o seu próprio corpo, a sua profissão, os seus direitos, deveres e suas vontades coloca em evidência a relação entre gênero, esporte e desenvolvimento.

Depois da apresentação resumida das categorias de análise, selecionamos títulos de textos publicados pelo blog para exemplificar esses recortes. Na categoria posicionamento, serão consideradas as notícias que se posicionam contra ou a favor de algo - exemplo: "A hipocrisia do Corinthians com Juninho absolve a violência contra a mulher"; na categoria gênero em profundidade, serão consideradas as notícias que incentivam a reflexão a partir de um problema de gênero no contexto esportivo - exemplo: "Unidas, jogadoras da Nova Zelândia igualaram salários e derrubaram o técnico"; por fim, na categoria empoderamento, serão consideradas notícias que garantem o lugar de fala das atletas e valorizam iniciativas no âmbito do esporte - exemplo: "Marta e mais nove: quem são e onde jogam as melhores do mundo".

No item a seguir, apontamos o corpus escolhido e iniciamos a análise, que contemplará ainda uma segunda etapa para identificar a origem (homens ou mulheres) dos comentários feitos no blog e a natureza (positivos ou negativos) deles.

\section{DEFINIÇÃO DO CORPUS E ANÁLISE}

0 corpus deste artigo contempla as publicações referentes à Copa do Mundo da Rússia - período que vai de 14 de junho a 14 de julho de 2018 - no blog dibradoras, o que reuniu um total de 20 textos cujos títulos serão classificados. Optamos por não utilizar todo o conteúdo, pois este é apenas o recorte de nossa tese sobre o que chamamos aqui de contracobertura esportiva ou cobertura esportiva feminista. Baseamo-nos em Bardin (2011) e Bauer (2008) para 
realizar a categorização, a classificação dos dados e as análises parcial e primária, que devem contribuir para apontamentos futuros - desde hipóteses confirmadas e caminhos a serem revistos.

Segundo Bauer (2008), a análise de conteúdo é um método de análise de texto desenvolvido nas ciências sociais empíricas. De acordo com ele, a análise de texto faz "uma ponte entre um formalismo estatístico e a análise qualitativa dos materiais. 0 divisor quantidade/qualidade das ciências sociais, a análise de conteúdo é uma técnica híbrida que pode mediar esta improdutiva discussão sobre virtudes e métodos". ${ }^{24}$ Bardin (2011) completa assegurando que, enquanto método, ela se torna um conjunto de técnicas que utiliza procedimentos sistemáticos e objetivos para descrever o conteúdo das mensagens.

Nas tabelas a seguir, elencamos quantos e quais títulos se enquadram nas categorias anteriormente apresentadas, a quantidade de comentários, ${ }^{25}$ a natureza deles (positivo, negativo, neutro ${ }^{26}$ ) e o gênero (se a pessoa se identifica como homem, mulher ou indefinido ${ }^{27}$ ). Decidimos fazê-los de maneira unificada, a fim de facilitar a leitura dos dados.

\begin{tabular}{|c|c|c|c|}
\hline Posicionamento (total: sete títulos) & $\begin{array}{l}\text { Qtd. } \\
\text { Comentários }\end{array}$ & Natureza & Gênero \\
\hline $\begin{array}{l}\text { Irã estreia na Copa, mas fora de campo já sai } \\
\text { derrotado }\end{array}$ & 1 & negativo & indefinido \\
\hline $\begin{array}{l}\text { Como Tite transformou geração ruim em } \\
\text { favorita ao título da Copa }\end{array}$ & 1 & negativo & homem \\
\hline $\begin{array}{l}\text { Mulheres deixaram de ser coadjuvantes e } \\
\text { iniciam era de protagonismo na Copa }\end{array}$ & 4 & 4 neutros & $\begin{array}{l}3 \text { homens; } \\
1 \text { indefinido }\end{array}$ \\
\hline $\begin{array}{l}\text { Não é uma disputa: nem futebol feminino nem } \\
\text { masculino, apenas futebol }\end{array}$ & 1 & positivo & mulher \\
\hline $\begin{array}{l}\text { Fifa, o problema não é a beleza delas, é a falta } \\
\text { de respeito deles }\end{array}$ & 0 & - & - \\
\hline $\begin{array}{l}\text { Brasileiros precisam entender que assédio não } \\
\text { é brincadeira }\end{array}$ & $\begin{array}{l}168 \text { (mas } \\
\text { apenas } 119 \\
\text { aparecem) }\end{array}$ & $\begin{array}{l}62 \text { positivos } \\
44 \text { negativos } \\
13 \text { neutros }\end{array}$ & $\begin{array}{l}88 \text { homens; } \\
18 \text { indefinidos; } \\
13 \text { mulheres; }\end{array}$ \\
\hline
\end{tabular}

\footnotetext{
${ }^{24}$ BAUER. Análise de conteúdo clássica: uma revisão, p. 190.

${ }^{25}$ Comentários feitos até o dia 27 set. 2018.

${ }^{26}$ Consideramos "neutro" o comentário que se isenta de posicionamento ou não faz referência nenhuma ao tema da notícia.

${ }^{27}$ Observamos 0 nome do usuário e a concordância nominal presente no texto quanto ao gênero.
} 


\begin{tabular}{|c|c|c|c|}
\hline \multicolumn{4}{|l|}{ Gênero em profundidade (total: oito títulos) } \\
\hline $\begin{array}{l}\text { "Para muitos, mulher falando de futebol ainda é } \\
\text { aberração" }\end{array}$ & $\begin{array}{l}15 \text { (mas só } 11 \\
\text { aparecem) }\end{array}$ & $\begin{array}{l}8 \text { negativos } \\
2 \text { positivos } \\
1 \text { neutro } \\
\end{array}$ & $\begin{array}{l}5 \text { indefinidos; } \\
4 \text { homens; } \\
2 \text { mulheres }\end{array}$ \\
\hline $\begin{array}{l}\text { Mulheres relatam assédio e abusos no país da } \\
\text { Copa }\end{array}$ & $\begin{array}{l}19 \text { (mas só } 9 \\
\text { aparecem) }\end{array}$ & $\begin{array}{l}5 \text { negativos } \\
2 \text { neutros } \\
2 \text { positivos }\end{array}$ & 9 homens \\
\hline $\begin{array}{l}\text { A transformação da torcida brasileira na Copa } \\
\text { da Rússia }\end{array}$ & 0 & - & - \\
\hline A experiência da Copa sozinha & 6 & $\begin{array}{l}4 \text { positivos } \\
1 \text { neutro } \\
1 \text { negativo }\end{array}$ & $\begin{array}{l}2 \text { homens } \\
2 \text { indefinidos } \\
1 \text { mulher }\end{array}$ \\
\hline $\begin{array}{l}\text { Por que não há mulheres na arbitragem da } \\
\text { Copa nem no VAR }\end{array}$ & $\begin{array}{l}42 \text { (mas só } 23 \\
\text { aparecem) }\end{array}$ & $\begin{array}{l}20 \text { negativos } \\
2 \text { positivos } \\
1 \text { neutro }\end{array}$ & $\begin{array}{l}16 \text { homens; } \\
5 \text { indefinidos; } \\
2 \text { mulheres }\end{array}$ \\
\hline $\begin{array}{l}\text { Onde mulheres, negros e gays têm vez na } \\
\text { Copa da Rússia }\end{array}$ & 1 & positivo & homem \\
\hline $\begin{array}{l}\text { A história por trás da foto mais emblemática } \\
\text { dessa Copa }\end{array}$ & 2 & 2 negativos & 2 homens \\
\hline $\begin{array}{l}\text { A Fifa descobriu o assédio na Copa do Mundo: } \\
\text { o que isso pode mudar? }\end{array}$ & 1 & negativo & homem \\
\hline
\end{tabular}

Tabela 2: Categoria gênero e profundida; títulos selecionados do blog dibradoras.

\begin{tabular}{llll}
\hline Empoderamento (total: seis títulos) & & & \\
\hline $\begin{array}{l}\text { Copa do Mundo: abertura histórica tem primeira } \\
\text { narração feminina }\end{array}$ & $\begin{array}{l}\text { 8 positivos } \\
\text { 9 negativos }\end{array}$ & $\begin{array}{l}13 \text { homens; } 3 \\
\text { indefinidos; } 0 \\
\text { mulheres }\end{array}$ \\
$\begin{array}{l}\text { Demoramos, mas chegamos ao primeiro jogo } \\
\text { da seleção narrado por uma mulher }\end{array}$ & $\begin{array}{l}50 \text { (mas } \\
\text { apenas 38 } \\
\text { aparecem) }\end{array}$ & $\begin{array}{l}31 \text { negativos } \\
7 \text { positivos }\end{array}$ & $\begin{array}{l}24 \text { homens; } 10 \\
\text { indefinidos; } 4 \\
\text { mulheres }\end{array}$ \\
$\begin{array}{l}\text { Ex-capitã da seleção: o que o Brasil precisa } \\
\text { mudar contra a Costa Rica }\end{array}$ & 1 & positivo & homem \\
$\begin{array}{l}\text { Pode abaixar o volume, Terry. Vai ter mulher } \\
\text { narrando no Reino Unido também }\end{array}$ & 1 & negativo & homem \\
\hline $\begin{array}{l}\text { Argentinas promovem transmissão feminista da } \\
\text { Copa com debate de gênero }\end{array}$ & 1 & positivo & mulher \\
\hline $\begin{array}{l}\text { Final da Copa do Mundo terá mulher na } \\
\text { comissão técnica. E não é a primeira vez }\end{array}$ & 0 & - & - \\
\hline
\end{tabular}

Tabela 3: Categoria empoderamento; títulos selecionados do blog dibradoras.

Depois de categorizar as informações sobre os títulos e comentários nas tabelas, apresentamos aqui nossas impressões.

Identificamos que a categoria gênero em profundidade apresentou mais textos sendo comentados, são eles: "Por que não há mulheres na arbitragem da Copa nem no VAR", com 23; "Mulheres relatam assédio e abuso no país da Copa", com nove; e "Para muitos, mulher falando de futebol ainda é aberração", com 11.

No entanto, o texto com maior número de comentários está na categoria posicionamento - "Brasileiros precisam entender que assédio não é brincadeira", 
com 119 -, mas acreditamos que a temática da publicação, que revelou o vazamento de um vídeo de brasileiros assediando torcedoras russas, impulsionou essa interação. 0 segundo texto mais comentado aparece na categoria empoderamento e colocou em pauta um fato inédito ("Demoramos, mas chegamos ao primeiro jogo da seleção narrado por uma mulher", com 38), quando uma transmissão totalmente feminina foi promovida pelo canal Fox Sports 2 para o jogo de estreia da seleção brasileira de futebol masculino, contra a Suíça. A quantidade de comentários negativos feitos por indivíduos do gênero masculino confirma o contexto de preconceito e dificuldades no qual se dá a relação entre mulheres e esporte.

Dentre os 20 textos selecionados, apenas seis receberam quantidade significativa de comentários. Todos eles tratavam dos temas assédio e mulheres narrando ou comentando sobre futebol. No entanto, dois deles chamaram a atenção: em "Brasileiros precisam entender que assédio não é brincadeira", tivemos um total de 62 comentários positivos, que reforçavam o título e a proposta de discussão do texto; em "Copa do Mundo: abertura histórica tem primeira narração feminina", a divisão das reações foi muito próxima (nove comentários negativos e oito positivos), também com maioria masculina.

Esses dados mostram que, apesar da representativa quantidade de comentários negativos, existe uma sinalização positiva para determinados assuntos. Porém, em ambos os casos, os comentários faziam comparações: no primeiro, argumentavam que a mulher assediada poderia ser mãe, irmã ou esposa de alguém desconsiderando o fato de que mulher alguma deveria lidar com qualquer tipo de assédio; no outro, a narradora em questão foi diversas vezes elogiada em comparações com o narrador Galvão Bueno, como no exemplo "só é melhor que o chato do Galvão" - o que transforma o elogio em uma espécie de consolo.

Outro título que também tratava do mesmo assunto, "Demoramos, mas chegamos ao primeiro jogo da seleção narrado por uma mulher", revelou resultados distintos, com 38 comentários negativos. A diferença entre os dois é que o primeiro foi posto de maneira impessoal, já o segundo soa como uma argumentação na terceira pessoa do plural, com mais personalidade e opinião na fala - o que talvez promova um caráter mais desafiador? Ou trave um diálogo direto com quem lê e comenta? 


\section{CONSIDERAÇõES FINAIS}

Neste artigo, refletimos brevemente sobre os movimentos sociais em rede, as novas demandas da sociedade que influenciam a comunicação e o acesso à informação, além das possibilidades de articulação contra padrões, ideias ou comportamentos preestabelecidos, com foco no cenário esportivo e parte de suas problemáticas.

A partir dessas discussões, estabelecemos o período de cobertura da Copa do Mundo da Rússia para análise, com observações que apresentaram um caráter mais qualitativo e introdutório, se considerarmos o objetivo de compreender todas as especificidades da cobertura que tratamos como pioneira dentro do jornalismo esportivo. Por isso, ressaltamos que esses foram apenas os passos iniciais e as primeiras tentativas de consolidar a metodologia e as categorias que pretendemos utilizar no desenvolvimento de nossa tese, por isso ainda prevemos muitas mudanças e adequações até o resultado final.

Refletimos sobre as ideias de pertencimento e envolvimento com o objeto de pesquisa, a cobertura feminista com posicionamento, os problemas de gênero atrelados ao esporte, assim como examinamos os diferentes significados de empoderamento, com o objetivo de associar esses processos às categorias definidas de acordo com a análise de conteúdo proposta por Bardin (2011) e Bauer (2008). Nas categorias elencadas - "posicionamento", "gênero em profundidade" e "empoderamento" -, classificamos os títulos de 20 textos que compuseram o corpus e encontramos quantidades próximas em cada uma delas (sete, oito e seis títulos respectivamente).

Nos comentários, de um total de 214 analisados apenas 90 tiveram abordagem positiva ou neutra. Os títulos que propunham debate ou continham linguagem pessoal ("demoramos, mas chegamos"), provocaram mais comentários negativos, assim como aqueles que tratavam de assédio ou críticas à ausência de mulheres em determinados espaços. Por fim, ainda que a interação negativa tenha sido superior, entendemos que seja esse o caminho: causar incômodo e promover a reflexão para gerar novas percepções sobre a ordem e os padrões sociais aos quais estamos condicionados. 


\section{REFERÊNCIAS}

BARDIN, Laurence. Análise de conteúdo. São Paulo: Edições 70, 2011.

BAUER, Martin W. Análise de conteúdo clássica: uma revisão. In: Bauer, Martin W.; Gaskell, George (org). Pesquisa qualitativa com texto, imagem e som: um manual prático. Petrópolis: Vozes, 2008, p.189-217.

CASTELLS, Manuel. Redes de indignação e esperança: movimentos sociais na era da internet. Rio de Janeiro: Editora Zahar, 2012.

GOELLNER, Silvana. Mulheres e esporte: sobre conquistas e desafios. Revista do Observatório Brasil da Igualdade de Gênero, v. 2, n. 4, 2012.

GOELLNER, Silvana. Mulher e esporte no Brasil: Entre incentivos e interdições elas fazem história. Pensar a prática, v. 8, n. 1, 85-100, 2005.

LEÓN, Magdalena. El empoderamiento en la teoría y práctica del feminismo. In: LÉON, Magdalena. (Org). Poder y empoderamiento de las mujeres. Bogotá: Tercer Mundo Editores - Universidad Nacional de Colombia, 2005, p. 25-45.

NEVES, Sofia; NOGUEIRA, Conceição. A psicologia feminista e a violência contra as mulheres na intimidade: a (re)construção dos espaços terapêuticos. Psicologia \& Sociedade, v. 15, n. 2, p. 43-64, 2003.

SARDENBERG, Cecilia. Da crítica feminista à ciência a uma ciência feminista?. In: COSTA, Ana Alice Alcântara; SARDENBERG, Cecilia. (Org). Feminismo, ciência e tecnologia. Salvador: REDOR/NEIM-FFCH/UFBA, 2002, p. 89-120.

WENSING, E. H.; BRUCE, T.; POPE, C. Playing to win or trying your best: Media representations of national anxieties over the role of sport participation during the 2002 Commonwealth Games. Waikato Journal of Education, n.10, 2004, p. 203-219. Disponível em: http://bit.ly/30iedwr. Acesso em: 13 maio 2019. 